\title{
Calicivírus animal
}

\section{Animal caliciviruses}

\section{Aline Fernandes Barry ${ }^{1}$; Alice Fernandes Alfieri²; Amauri Alcindo Alfieri ${ }^{3 *}$}

\section{Resumo}

Os calicivírus eram classificados como membros da família Picornaviridae e somente em 1979 foi proposta a criação da família Caliciviridae. Nessa família estão incluídos quatro gêneros: Vesivirus, Lagovirus, Norovirus e Sapovirus sendo o genoma constituído de uma molécula de RNA fita simples, linear, de polaridade positiva, poliadenilado na extremidade 3'. O gênero Vesivirus compreende vírus causadores de doenças vesiculares em felinos (FCV), suínos (VESV) e cetáceos e pinípedes (SMSV). Os lagovírus incluem o European brown hare syndrome virus (EBHSV) e o Rabbit hemorrhagic disease virus (RHDV) que acometem lebres e coelhos causando doença hepática. Os norovírus, anteriormente denominados Norwalk-like virus, são considerados os mais importantes causadores de gastroenterite não-bacteriana em seres humanos adultos e crianças em países da Europa, nos Estados Unidos e Japão. Os hospedeiros naturais dos norovírus são os seres humanos, bovinos, suínos e ratos. Os sapovírus são descritos em seres humanos e suínos, e principalmente os indivíduos jovens são acometidos. Em seres humanos a infecção pelos sapovírus se manifesta como uma diarréia moderada e em suínos já foi verificada atrofia das vilosidades intestinais e diarréia em leitões experimentalmente infectados com a estirpe padrão Cowden. Apesar da grande variabilidade genética descrita nos sapovírus, já foram descritas recombinações entre estirpes de genogrupos e genotipos diferentes, existindo a possibilidade do potencial zoonótico da doença.

Palavras-chave: Suíno, leitão, diarréia, enterite, calicivírus, sapovírus

\begin{abstract}
The caliciviruses were included in Picornaviridae family, and only in 1979 they were classified as Caliciviridae members. There are four genera included in this family: Vesivirus, Lagovirus, Norovirus and Sapovirus. Its genome consists of a single-stranded poly-adenylated RNA molecule with positive polarity. The Vesivirus genus includes viruses that cause vesicular disease in feline (FCV), swine (VESV) and cetacean and piniped (SMSV). Lagoviruses include the European brown hare syndrome virus (EBHSV) and Rabbit hemorrhagic disease virus (RHDV) which infects hare and rabbits causing hepatic disease. The noroviruses, previously named, Norwalk-like virus, are the main cause of nonbacterial human gastroenteritis in some European countries, United States and Japan. The natural hosts of this virus are the man, bovine, swine, and rats. Sapovirus infects human and swine, especially the young. In human the infection is normally a mild diarrhea. In swine it has been described intestinal villous atrophy and diarrhea in experimental infected piglets. Despite the high genetic variability of sapoviruses, recombination between strains from different genogroups or genotypes was already verified, which suggests the zoonotic potential of the disease.
\end{abstract}

Key words: Swine, piglet, diarrhea, enteritis, calicivirus, sapovirus

Parte integrante da dissertação da primeira autora pelo Programa de Pós-graduação em Ciência Animal, UEL.

Professor do Departamento de Medicina Veterinária Preventiva / UEL.

Professor do Departamento de Medicina Veterinária Preventiva / UEL. E-mail: alfieri@uel.br

Autor para correspondência 


\section{Histórico}

A primeira descrição da infecção pelo calicivírus em animais ocorreu em 1932 com o vírus do exantema vesicular dos suínos (VESV). O vírus foi considerado o agente etiológico de uma epidemia nos Estados Unidos que ocasionou a perda de 2,5 milhões de suínos pela morte, abortamento e abate para erradicar a doença. O último relato da enfermidade ocorreu em 1956 no Estado da Califórnia e em 1959 a doença foi considerada erradicada (CUBITT, 1994).

Os norovírus foram primeiramente descritos no ano de 1972 e estavam associados ao primeiro surto da doença, em 1968, em que alunos e professores de uma escola em Norwalk no Estado de Ohio, EUA, apresentaram vômito e diarréia. Porém, somente em 1981 foram classificados como calicivírus (ADLER; ZICKL, 1968; KAPIKIAN et al., 1972; GREENBERG et al., 1981; ATMAR; ESTES, 2001). Já os calicivírus com morfologia clássica, atualmente classificados como sapovírus, foram detectados em seres humanos em 1976 em amostras de fezes de crianças com gastroenterite e assintomáticas (MADELEY; COSGROVE, 1976).

Os calicivírus foram inicialmente classificados como membros da família Picornaviridae. Burroughs e Brown (1974) propuseram a criação da família Caliciviridae devido aos calicivírus apresentarem características morfológicas distintas dos picornavírus, como tamanho e densidade das partículas virais, além da composição do capsídeo em somente uma proteína (BURROUGHS; BROWN, 1974). Outros estudos complementaram essa nova classificação com base na detecção de diferentes tamanhos de RNA viral, a partir de células infectadas com calicivírus, demonstrando diferenças na replicação em relação aos picornavírus (EHRESMANN; SCHAFFER, 1977). Essa nova classificação foi descrita no Terceiro Relatório do Comitê Internacional de Taxonomia Viral, em 1979, (CUBITT, 1994).
Os lagovírus foram detectados em 1984, na China, como um vírus de morfologia semelhante ao VESV ocasionando surtos de doença hemorrágica em criações de coelhos (BASCUÑANA; NOWOTNY; BELÁK, 1997) e mais tarde em lebres na Itália (WIRBLICH et al., 1994).

\section{Características Gerais}

A família Caliciviridae é constituída de quatro gêneros: Vesivirus, Lagovirus, Norovirus (NoV) e Sapovirus (SaV) (Quadro 1 e Figura 1). Todos os membros não possuem envelope lipoprotéico, apresentam simetria icosaédrica e diâmetro variando de 27 a $39 \mathrm{~nm}$. A densidade das partículas virais em $\mathrm{CsCl}$ é de 1.33-1.4 $\mathrm{g} \mathrm{cm}^{-3}$, sendo sensíveis ao tratamento com tripsina, porém resistentes em faixas de $\mathrm{pH}$ de 4 a 5 (INTERNATIONAL COMMITTEE ON TAXONOMY OF VIRUSES - ICTV, 2007). Os calicivírus podem ser classificados em vírus com morfologia clássica, compostos por 32 depressões no capsídeo, e vírus com estrutura arredondada (small round structured virus - SRSV) (Figura 2). O genoma é constituído por RNA fita simples, linear, de polaridade positiva, poliadenilado na extremidade 3' e com tamanho variando de 7,4 a $8,3 \mathrm{~kb}$. Na extremidade 5' de algumas estirpes virais há uma proteína (VPg), de aproximadamente 16 $\mathrm{kDa}$, ligada covalentemente. A VPg está presente tanto no RNA genômico quanto no subgenômico, este último transcrito para codificar as proteínas estruturais do vírus (WIRBLICH; THIEL; MEYERS, 1996; SOSNOVTSEV; GARFIELD; GREEN, 2002; BELLIOT et al., 2003; OKA et al., 2005). A organização do genoma pode ser em duas ou três regiões abertas de leitura (open reading frames-ORFs), em que são codificadas as proteínas não-estruturais e estruturais do vírus (ICTV, 2007; GREEN et al., 2000). 


\begin{tabular}{|c|c|c|c|c|c|c|}
\hline Família & Gênero & Espécie & Hospedeiro & Ano & País & Referência \\
\hline \multirow[t]{21}{*}{ Caliciviridae } & Lagovirus & European brown hare syndrome virus & Lebre & 1989 & Itália & Lavazza e Vecchi, 1989 \\
\hline & & Rabbit hemorrhagic disease virus & Coelho & 1984 & China & Liu et al., 1984 \\
\hline & Norovirus & Norwalk virus & Humano & 1972 & EUA & Kapikian et al., 1972 \\
\hline & & Não-classificados & Bovino & 1978 & $\begin{array}{l}\text { Reino } \\
\text { Unido }\end{array}$ & Almeida, Craig e Hall, 1978 \\
\hline & & & Suíno & 1998 & Japão & Sugieda et al., 1998 \\
\hline & & & Rato & 2003 & EUA & Karst et al., 2003 \\
\hline & Sapovirus & Sapporo virus & Humano & 1976 & $\begin{array}{l}\text { Reino } \\
\text { Unido }\end{array}$ & Madeley e Cosgrove, 1976 \\
\hline & & Não-classificados & Marta & 2001 & Canadá & Guo, Evermann e Saif, 2001 \\
\hline & & & Suíno & 1980 & EUA & Saif et al., 1980 \\
\hline & Vesivirus & Calicivírus felino & Felino & 1957 & EUA & Fastier, 1957 \\
\hline & & Vírus do exantema vesicular suíno & Bovino & 1983 & EUA & Smith et al., $1983 \mathrm{a}^{\mathrm{a}}$ \\
\hline & & & Gambá & 1995 & EUA & Seal et al., 1995 \\
\hline & & & Leão Marinho & 1972 & EUA & Smith et al., 1973 \\
\hline & & & Primata & 1983 & EUA & Smith et al., $1983 b$ \\
\hline & & & Réptil & 1986 & EUA & Smith et al., 1986 \\
\hline & & & Suíno & 1932 & EUA & Mohler e Snyder, 1933 \\
\hline & & Não-classificados & Marta & 1980 & EUA & Long, Evermann e Gorham, 1980 \\
\hline & & & Coelho & 2005 & Espanha & Martin-Alonso et al., 2005 \\
\hline & Não-classificados & Calicivírus aviário & Frango & 1981 & $\begin{array}{l}\text { Reino } \\
\text { Unido }\end{array}$ & Gough e Spackman, 1981 \\
\hline & & Calicivírus canino & Cão & 1985 & Japão & Schaffer et al., 1985 \\
\hline & & Nebraska & Bovino & 1980 & EUA & Smiley et al, 2002 \\
\hline
\end{tabular}

Quadro 1. Classificação dos gêneros e espécies virais pertencentes à família Caliciviridae.

\section{Vesivírus}

O gênero Vesivirus compreende vírus causadores de doenças em animais, sendo todos adaptados em culturas celulares. Todos se apresentam, à microscopia eletrônica, como calicivírus clássicos, ou seja, a superfície do capsídeo é formada por depressões que se assemelham a cálices. O calicivírus felino (FCV), que é responsável por doenças do trato respiratório superior e ulcerações orais em gatos, é um dos vírus mais estudados, sendo suas características antigênicas bem conhecidas (THUMFART; MEYERS, 2002). Também faz parte desse gênero o vírus do exantema vesicular dos suínos (VESV), que nos animais infectados ocasiona sinais clínicos indistingüíveis aos da estomatite vesicular (Vesiculovirus - Rhabdoviridae), doença vesicular dos suínos (Enterovirus - Picornaviridae) e da febre aftosa (Aphtovirus - Picornaviridae). As lesões vesiculares podem estar presentes no focinho, lábios, língua, cavidade oral, patas, espaço interdigital e borda coronária do casco. Não raramente, podem ocorrer problemas reprodutivos como abortamento, havendo também relatos de diarréia grave (MADIN; TRAUM, 1955). Outro vesivírus de grande importância é o San Miguel sea lion virus (SMSV), que ocasiona sinais clínicos em cetáceos e pinípedes (focas, leões marinhos) muito semelhantes aos presentes em suínos infectados com o VESV. Há também características antigênicas em comum entre ambos os vírus (NEILL; MEYER; SEAL, 1995). A transmissão inter-espécies já foi descrita entre focas, martas e suínos por meio da ingestão de alimentos e fezes contaminados com o SMSV (WILDER; DARDIRI, 1978). A organização genômica desses vírus se faz em três ORFs. Na ORF1 é codificada uma poliproteína que é clivada, simultaneamente à sua síntese, pela protease viral originando as proteínas não-estruturais do vírus. As ORF2 e ORF3 codificam as proteínas estruturais VP1 (principal) e VP2 (secundária), respectivamente (GREEN et al., 2000). 


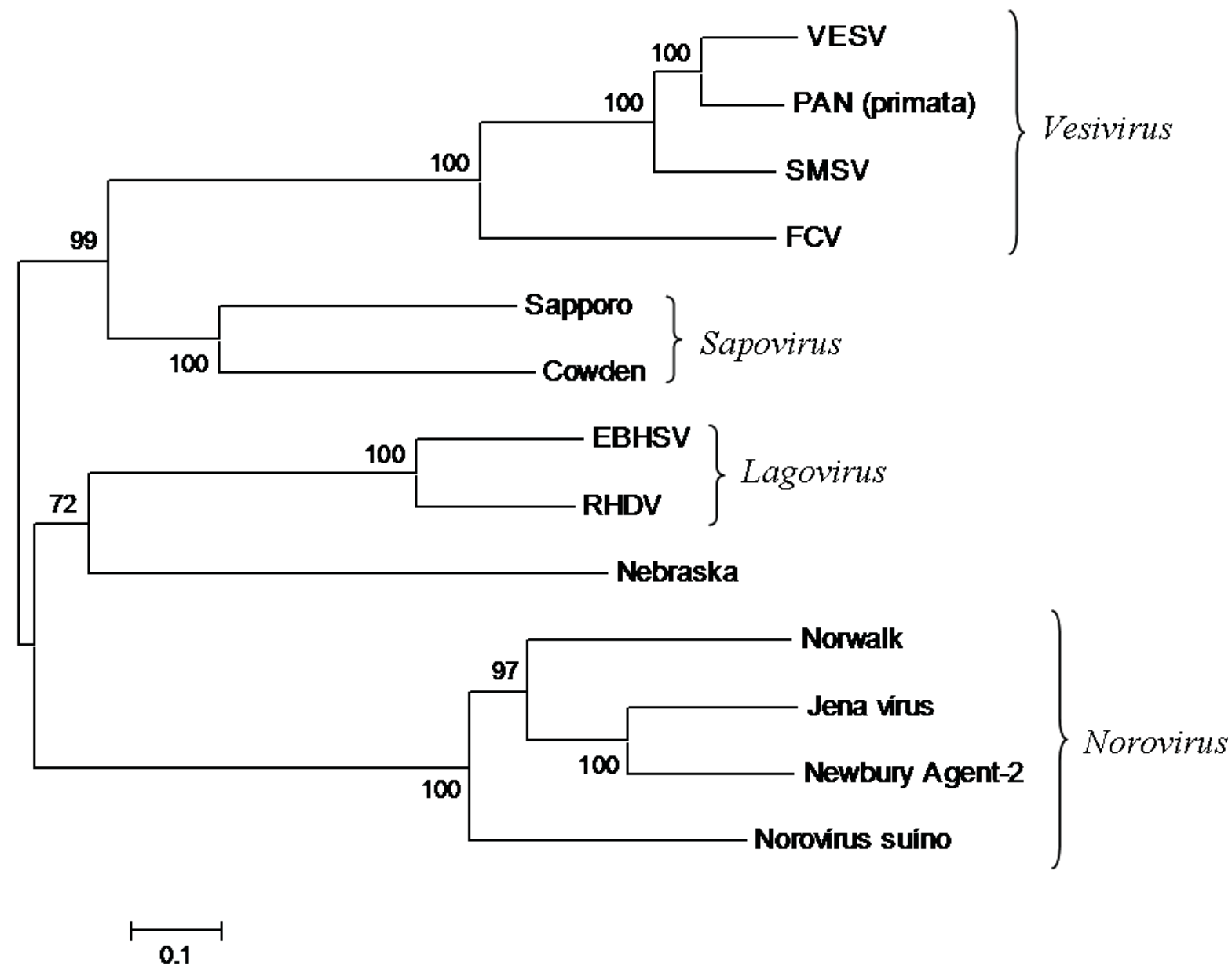

Figura 1. Árvore filogenética (neighbor-joining) baseada no genoma parcial (2.626 nt) dos principais membros da família Caliciviridae, representando os quatro gêneros e a estirpe Nebraska (ainda não classificada). Reconstrução em Kimura 2-parâmetro com valores de bootstrap em \% (1000 replicações). Seqüências obtidas do GenBank com os seguintes códigos de acesso: VESV (AF181082); PAN (AF091736); SMSV (AF181081); FCV (M86379); Sapporo (U65427); Cowden (AF182760); EBHSV(Z69620); RHDV(M67473); Nebraska (AY082891); Norwalk (M87661); Jena vírus (AJ011099); Newbury Agent-2 (AF097917) e Norovírus suíno (AB074893).

\section{Lagovírus}

Os lagovírus incluem o European brown hare syndrome virus (EBHSV) e o Rabbit hemorrhagic disease virus (RHDV). Tanto lebres quanto coelhos infectados apresentam sinais clínicos bastante semelhantes decorrentes da degeneração dos hepatócitos, que resulta em necrose hepática. A taxa de mortalidade é bastante elevada podendo alcançar $100 \%$ em animais adultos. Morfologicamente o EBHSV e o RHDV são indistingüíveis e semelhanças antigênicas entre eles também já foram demonstradas utilizando-se soro hiperimune de coelhos infectados com o RHDV. Até o momento não foi possível adaptar em cultivo celular nenhuma estirpe identificada de lagovírus. O EBHSV e o RHDV podem se diferenciados por imunomicroscopia eletrônica, hemaglutinação e ELISA demonstrando que esses vírus, apesar de bastante relacionados, apresentam algumas diferenças antigênicas. A organização genômica ocorre em duas ORFs, sendo que na primeira são codificadas as proteínas não-estruturais e a proteína principal do capsídeo e na segunda uma proteína estrutural secundária (OHLINGER et al., 1990; WIRBLICH et al., 1994). 


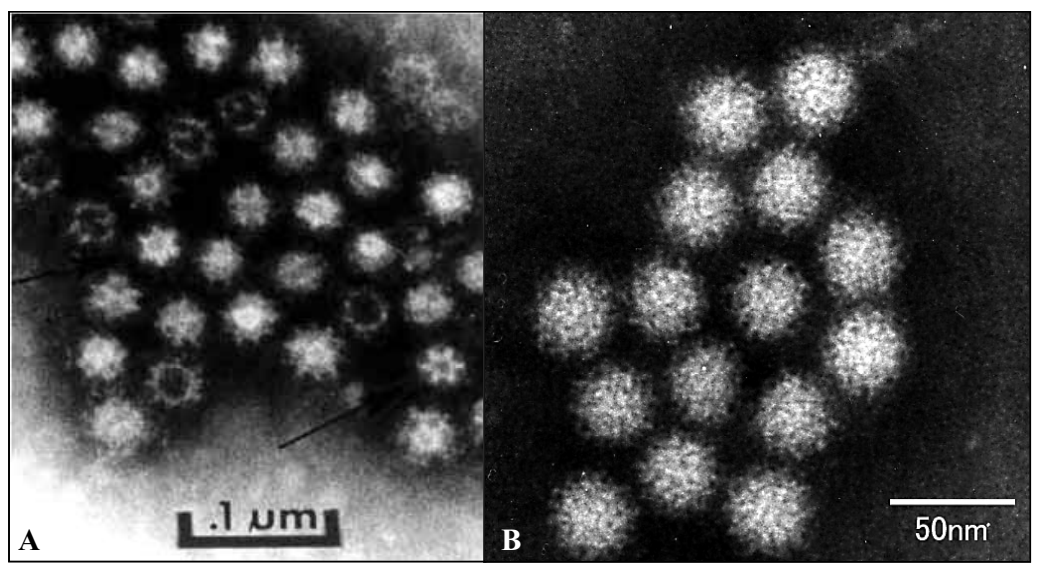

Figura 2. Microscopia eletrônica de contrastação negativa das duas estruturas morfológicas dos calicivírus. (A) Morfologia clássica com 32 depressões (cálices) ou em "Estrela-de-Davi", presente nos vesivírus, lagovírus e sapovírus. (B) Small round structured virus. Estrutura dos norovírus e alguns calicivírus felinos.

Fonte: http://researchnews.osu.edu/archive/calici.jpg e http://www.pref.ehime.jp/040hokenhukushi/140eikanken/ kanjyo/topics/ityoen/image/norovirus-1.jpg.

\section{Norovírus}

Os NoV, anteriormente denominados Norwalklike virus, são considerados os mais importantes causadores de gastroenterite não-bacteriana em adultos e crianças em países da Europa, nos Estados Unidos e Japão (INOUYE et al., 2000; FRANKHAUSER et al., 2002; LOPMAN et al., 2003). A transmissão pode ocorrer pelo contato direto ou pela ingestão de água e alimentos contaminados (FRANKHAUSER et al., 1998). Em seres humanos a transmissão de NoV por meio da ingestão de moluscos e ostras contaminados também já foi relatada (COSTANTINI et al., 2006). Surtos de infecção em cruzeiros marítimos e em alojamentos improvisados devido a desastres ambientais também são descritos (CENTERS FOR DISEASE CONTROL AND PREVENTION - CDC, 2005; ISAKBAEVA et al., 2005). Embora a presença de anticorpos e a detecção do vírus já tenham sido verificadas, a prevalência e a epidemiologia da doença ainda não estão completamente estabelecidas (FRANKHAUSER et al., 2002; GALLIMORE et al., 2004; FARKAS et al., 2005). Os hospedeiros naturais dos NoVs são os seres humanos, bovinos, suínos e ratos (murine norovírus - MNV). Ratos infectados com o MNV constituem um importante modelo experimental animal para o estudo da replicação e patogenia dos $\mathrm{NoVs}$, uma vez que o MNV é o único NoV adaptado em cultivo celular e capaz de se replicar em animal de experimento (WOBUS; THACKRAY; VIRGIN IV, 2006). Morfologicamente os NoV são classificados como small round structured virus e têm a característica de apenas se propagarem em cultivos celulares específicos como células dendríticas e macrófagos (DUIZER et al., 2004; WOBUS et al., 2004). O genoma viral é organizado em três ORFs, sendo que as proteínas não-estruturais são formadas a partir da clivagem de uma poliproteína codificada na primeira ORF e as duas proteínas estruturais codificadas na segunda e terceira ORFs. Com base nas características moleculares, as estirpes de NoV são divididas em cinco genogrupos (ANDO; NOEL; FRANKHAUSER, 2000; ZHENG et al., 2006). Os membros dos genogrupos I, II e IV são causadores de surtos de gastroenterite em seres humanos. Porém, estirpes isoladas de amostras de fezes de suínos demonstraram maior similaridade genética com as estirpes de NoV humanos do GII. (SUGIEDA; NAKAJIMA, 2002). As estirpes de 
NoV bovinos estão classificadas no GIII, separado em dois genotipos cujos protótipos são o Jena vírus e o Newbury Agent-2 (DASTJERDI et al., 1999; LIU et al., 1999). Os NoV de ratos são classificados no GV.

\section{Sapovírus}

Os $\mathrm{SaVs}$, anteriormente denominados Sapporolike virus, têm como protótipo a estirpe Sapporo/82, descrita emum surto de gastroenterite em um orfanato na cidade de Sapporo no Japão em outubro de 1977. Esses vírus apresentam-se com a configuração de Estrela-de-Davi, ou seja, à microscopia eletrônica têm morfologia clássica, sendo por isso, também denominados de calicivírus humanos clássicos. Em seres humanos a infecção ocorre, principalmente, em crianças e a doença normalmente se manifesta como uma diarréia moderada, embora infecções assintomáticas também possam ocorrer. A excreção viral é maior nos primeiros cinco dias pós-infecção, nos quais o vírus pode ser detectado diretamente nas fezes por microscopia eletrônica, imunomicroscopia eletrônica ou RT-PCR. O isolamento do SaV humano em cultivo celular, até o momento, ainda não foi obtido. A imunidade humoral já foi detectada por até três meses pós-infecção. Porém, ainda não está estabelecido se os anticorpos realmente conferem proteção efetiva ou se esse aumento apenas reflete a infecção intestinal (CHIBA et al., 2000).

Infecções por SaV em seres humanos já foram detectadasempaíses daEuropa(SCHUFFENECKER et al., 2001), Américas (FARKAS et al., 2004), Ásia
(OKADA et al., 2002) e Oceania (HANSMAN et al., 2006) demonstrando a ampla circulação do vírus em todo o mundo. No Brasil, o vírus foi detectado em crianças com sinais clínicos de diarréia (NAKAMURA et al., 2006).

De acordo com o Grupo de Estudos de Calicivírus (CSG) do Comitê Internacional de Taxonomia Viral (ICTV), seqüências totais e parciais do genoma, associadas às características morfológicas, propriedades antigênicas, hospedeiros e sinais clínicos são aspectos suficientes para classificar uma estirpe viral de calicivírus, uma vez que a maioria dos calicivírus não são cultiváveis (GREEN et al., 2000). Também não há um modelo experimental animal descrito para $\mathrm{SaV}$ conhecendo-se, portanto, pouco sobre as estratégias de replicação, a patogenia e a resposta imunológica do hospedeiro.

O principal aspecto para o agrupamento dos calicivírus em um determinado gênero é a análise filogenética. Com base nas características moleculares da proteína principal do capsídeo, os sapovírus são classificados, filogeneticamente, em cinco genogrupos (Figura 3 e Quadro 2) (FARKAS et al., 2004). Embora não seja utilizado como padrão, essa mesma classificação se manteve nas análises moleculares realizadas em regiões dos genes da RNA polimerase RNA dependente (RpRd), ORF2, proteína principal de capsídeo e da região 3' nãotraduzida (UTR) (SCHUFFENECKER et al., 2001). Os representantes de cada genogrupo compartilham aspectos comuns da organização do genoma e o número de regiões abertas de leitura (GREEN et al., 2000). 


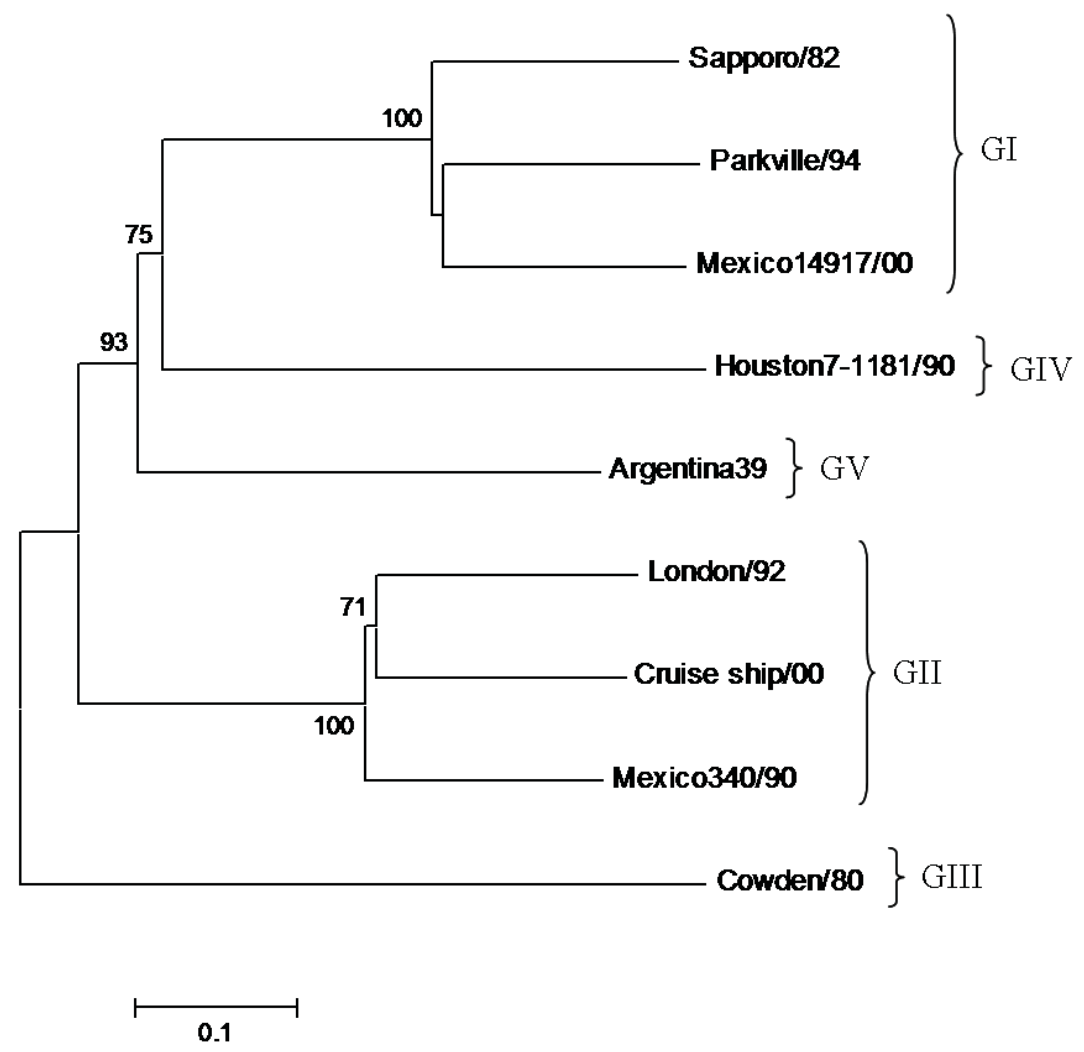

Figura 3. Reconstrução, em neighbor-joining, da árvore filogenética baseada no gene (1658 nt) da proteína principal do capsídeo de estirpes virais protótipos do gênero SaV. Modelo Kimura 2-parâmetro com valores de bootstrap em \% de 1000 replicações. As seqüências utilizadas foram obtidas no GenBank com os seguintes códigos de acesso: Sapporo/82 (U65427); Parkville/94 (U73124); Mexico14917/00 (AF435813); Houston7-1181/90 (AF435814); Argentina39 (AY289803); London/92 (U95645); Cruise ship/00 (AY289804); Mexico340/90 (AF435812) e Cowden/80 (AF182760). A divisão dos genogrupos está indicada nas chaves.

No genogrupo I (GI) o protótipo é a estirpe Sapporo/92.Essegenogrupoédivididoemtrêsgenotipos ou clusters, e as estirpes, embora com características filogenéticas bastante semelhantes, induzem respostas imunológicas distintas. A organização do genoma ocorre em duas ORFs, sendo que na primeira são codificadas as proteínas não-estruturais e a VP1 e na segunda a proteína estrutural VP2. Assim como nos genogrupos IV e V, no GI há uma terceira ORF sobreposta à região 5 ' do gene da proteína principal do capsídeo que codifica uma proteína de massa molecular semelhante à VP2. O genogrupo II (GII) é constituído de três genotipos, sendo este o único genogrupo humano em que não há a terceira ORF sobreposta (CLARKE; LAMBDEN, 2000).

As estirpes de $\mathrm{SaV}$ de origem suína são classificadas no genogrupo III (GIII) que tem como protótipo a estirpe Cowden, descrita pela primeira vez em 1980, nos Estados Unidos, por meio de microscopia eletrônica do conteúdo intestinal de um leitão de 27 dias de idade com sintomatologia de diarréia (SAIF et al., 1980). Neste mesmo estudo também foi verificado que soros hiperimunes de coelhos e gatos infectados com calicivírus não reagiram, à IEM, com o vírus identificado no conteúdo intestinal do leitão.

Assim como ocorre no SaV humano, a existência de mais de um genogrupo com estirpes suínas já foi proposta. Esses genogrupos são denominados GVI e GVII e tem como protótipos as estirpes JJ681 e K7/JP, respectivamente (WANG et al., 2005; YIN et al., 2006; WANG; COSTANTINI; SAIF, 2007). 


\begin{tabular}{llll}
\hline Sapovirus & Genotipo 1 & Genotipo 2 & Genotipo 3 \\
\hline Genogrupo I & Sapporo/82 & Houston/90 & Stockholm/97 \\
& Houston/86 & Parkville/94 & Mexico14917/00 \\
& Manchester/93 & & \\
& Plymouth/92 & & \\
& Lyon30388/98 & & Cruise ship/00 \\
Genogrupo II & London/92 & & \\
& Lyon598/97 & & \\
Genogrupo III* & Bristol/98 & & \\
Genogrupo IV* & Cowden/80 & & \\
Genogrupo V* & Houston7-1181/90 & & \\
\hline * Genogrupos na & Argentina39 & & \\
\hline
\end{tabular}

* Genogrupos não subdivididos em genotipos; Fonte: Farkas et al., 2004

Quadro 2. Distribuição das principais estirpes de sapovírus em genogrupos e genotipos, com base na seqüência do gene da proteína principal do capsídeo viral.

Em leitões experimentalmente infectados a estirpe selvagem Cowden, ou seja, não adaptada em cultivo celular, ocasionou quadro clínico de diarréia profusa e anorexia. A histopatologia revelou atrofia das vilosidades do epitélio do intestino delgado proximal e o vírus foi detectado por imunofluorescência direta (FLYNN; SAIF; MOORHEAD, 1988). A estirpe Cowden do SaV já foi adaptada a cultivo celular tanto em células primárias quanto linhagens celulares contínuas originadas de rim de suínos (LLC-PK) cultivadas em meio suplementado com conteúdos intestinais, provenientes de leitões gnobióticos não infectados (FLYNN; SAIF, 1988; PARWANI et al., 1991). Mais recentemente, constatou-se que ácidos biliares atuam como fator ativador da replicação viral em células LLC-PK (CHANG et al., 2004).

O genoma da estirpe Cowden já foi totalmente seqüenciado, e embora existam algumas mutações entre a estirpe selvagem e a estirpe adaptada em cultivo celular, a caracterização do vírus permitiu classificar algumas estirpes isoladas em outros surtos, como pertencentes ao mesmo genogrupo. A fita simples do RNA, excluindo a cauda de poli A da posição 3', é constituída de 7.320 nucleotídeos. O genoma é organizado em duas ORFs sendo que na primeira é codificada uma poliproteína cujos produtos da clivagem geram proteínas nãoestruturais e a proteína principal do capsídeo (VP1). Essa poliproteína é formada por 2.254 aminoácidos que darão origem a $2 \mathrm{C}$ helicase, $3 \mathrm{C}$-like protease, 3D RNA polimerase RNA dependente e a proteína estrutural de 544 aminoácidos, podendo a clivagem acontecer durante ou após a tradução. Sítios altamente conservados, característicos de proteínas não-estruturais dos calicivírus estão presentes na poliproteína: GPPGIGKT para 2C helicase, GDCG para 3C-like protease, GLPSG e YGDD para 3D RNA polimerase RNA dependente (Figura 4). A VPg ligada à extremidade 5' do genoma ainda não foi observada na estirpe Cowden. A VP1 pode ser dividida em três regiões sendo a primeira e a terceira 
as mais conservadas e a segunda chamada de região hipervariável, em que se determina a similaridade com outras estirpes para a caracterização de um novo isolado. Esta região contém múltiplos determinantes antigênicos que são reconhecidos por anticorpos monoclonais. A segunda ORF é formada por 495 nucleotídeos que codificam uma pequena proteína básica hidrofílica de 164 aminoácidos, provavelmente com função estrutural, e que por sua polaridade positiva interage com outras proteínas ou com o ácido nucléico viral (GUO et al., 1999).

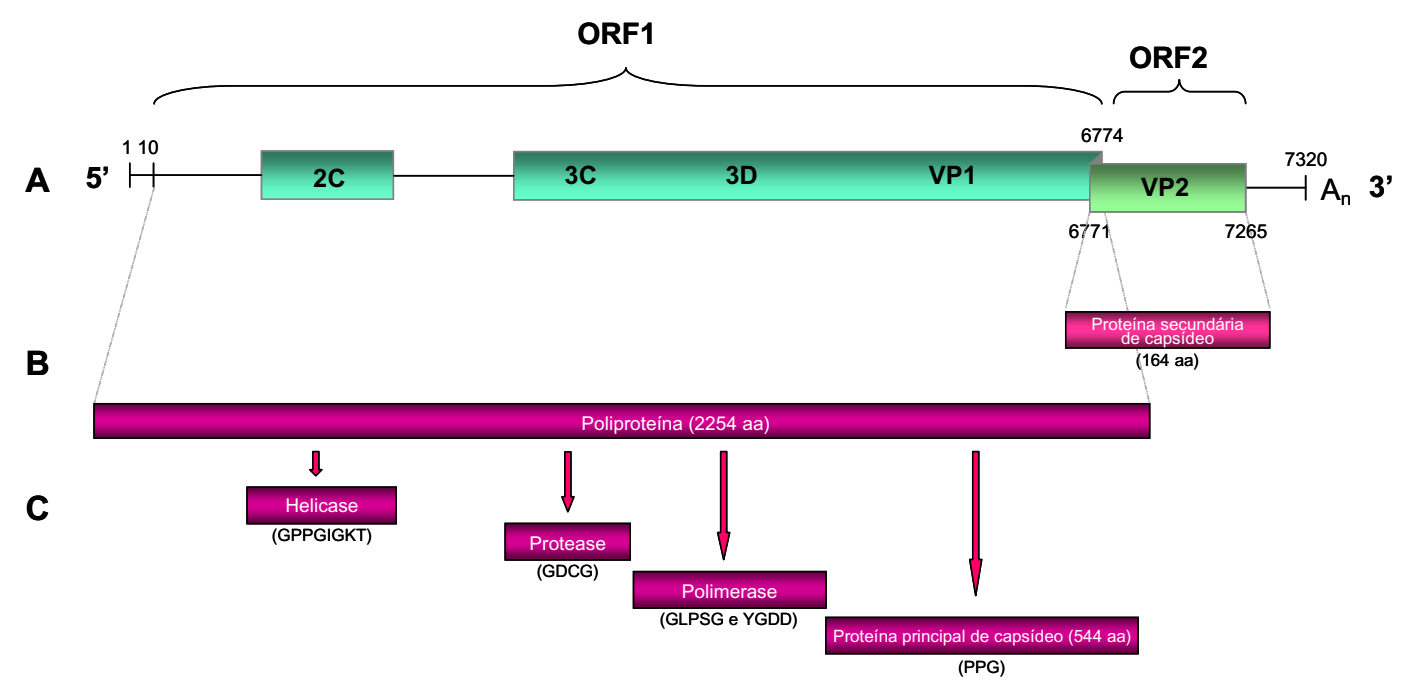

Figura 4. Esquema representativo do genoma da estirpe padrão Cowden do genogrupo III do SaV. (A) Representação das duas regiões de leitura do RNA viral na orientação $5^{\prime} \rightarrow 3$ ', em que os números representam a posição dos nucleotídeos e $\mathrm{A}_{\mathrm{n}}$ a extremidade poliadenilada. (B) Proteínas codificadas pelo vírus, entre parênteses o número de aminoácidos. (C) Produtos da clivagem da poliproteína com seus respectivos sítios conservados entre os calicivírus.

Devido a grande variabilidade dos calicivírus, diversos oligonucleotídeos iniciadores (primers) foram desenhados para amplificar diferentes regiões do genoma viral na tentativa de caracterizar as estirpes circulantes de SaV (JIANG et al., 1999; OKADA et al., 2006; WANG et al., 2006a).

Em suínos, utilizando-se a técnica da RT-PCR, o $\mathrm{SaV}$ já foi detectado no Brasil (BARRY; ALFIERI; ALFIERI, 2008), Coréia (KIM et al., 2006), Estados Unidos (WANG et al., 2006b), Holanda (van der HEIDE et al., número de acesso GenBank AY615812 e AY615814), Hungria (REUTER; BÍRÓ; SZÜCS, 2007), Japão (YIN et al., 2006) e Venezuela (MARTÍNEZ et al., 2006) (Quadro 3). No Brasil, apenas recentemente foi descrita a presença do $\mathrm{SaV}$ em amostras de fezes de leitões incluindo estirpes que, com base em um fragmento do gene RpRd viral, não apresentaram alta identidade com outras estirpes já descritas (BARRY, 2007). Nesse estudo não foi verificada associação entre a presença do vírus e o sinal clínico de diarréia, fato que pode ser justificado pela alta variabilidade genética das estirpes brasileiras que, embora causem infecção e sejam eliminadas nas fezes, talvez nem todas ocasionem o quadro clínico de diarréia. A freqüência da infecção pelo $\mathrm{SaV}$ é bastante variável (8,8 a 62\%), e embora existam poucos estudos epidemiológicos é possível que haja correlação entre a infecção e a idade dos animais. A idade provavelmente está mais relacionada a fatores extrínsecos, como estresse pós-desmame e queda na imunidade passiva, do que a fatores intrínsecos do animal (MARTÍNEZ et al., 2006; WANG et al., 2006b). Kim et al. (2006) correlacionaram a infecção pelo $\mathrm{SaV}$ com a presença de sinais clínicos de diarréia, assim como ocorreu em leitões experimentalmente infectados 
com a estirpe padrão Cowden (GUO et al., 1999). Porém, nos trabalhos conduzidos em outros países essa associação não foi observada (MARTÍNEZ et al., 2006; REUTER; BÍRÓ; SZÜCS, 2007; WANG et al., 2006b; YIN et al., 2006).

A alta similaridade genética com a estirpe padrão Cowden foi observada em pelo menos uma estirpe viral de cada país em que o $\mathrm{SaV}$ foi detectado nas fezes de suínos. Contudo, nem todos os isolados apresentaram identidade suficiente para serem classificados no mesmo genotipo do protótipo Cowden, sugerindo que, assim como nos $\mathrm{SaV}$ originados de seres humanos, existam mais de um genotipo do vírus suíno no GIII, ou até mais de um genogrupo de $\mathrm{SaV}$ suíno (MARTÍNEZ et al., 2006; KIM et al., 2006; REUTER; BÍRÓ; SZÜCS, 2007; WANG et al., 2005, 2006b; YIN et al., 2006). Além da alta taxa de mutação identificada nos $\mathrm{SaV}$, há ainda a descrição de recombinações virais entre estirpes suínas, aumentando a variabilidade genética, e entre estirpes humanas e suínas, sugerindo a probabilidade do potencial zoonótico do vírus (WANG et al., 2005).

Para serem esclarecidos mais aspectos referentes à patogenia e epidemiologia da infecção pelo $\mathrm{SaV}$ assim como melhor caracterização molecular das estirpes brasileiras, mais estudos estão sendo conduzidos nessas áreas.

\begin{tabular}{|c|c|c|c|c|c|c|c|}
\hline \multirow{2}{*}{ País } & \multirow{2}{*}{$\begin{array}{c}\text { Método } \\
\text { diagnóstico }\end{array}$} & \multirow{2}{*}{ Origem } & \multirow{2}{*}{ Idade } & \multirow{2}{*}{$\begin{array}{c}\text { Características } \\
\text { das fezes }\end{array}$} & \multicolumn{2}{|c|}{ Amostras } & \multirow{2}{*}{ Referência } \\
\hline & & & & & analisadas & $\begin{array}{c}\text { positivas } \\
(\%)\end{array}$ & \\
\hline Brasil & RT-PCR & 34 rebanhos & 1 a 28 dias & $\begin{array}{c}\text { diarréicas }(n=82) \\
\text { normais }(n=31)\end{array}$ & 113 & $34(30,1)$ & Barry, 2007 \\
\hline Coréia & nested-PCR & 31 rebanhos & $\begin{array}{c}\text { lactente }(n=50) \\
\text { desmamado } \\
(n=52)\end{array}$ & diarréicas & 102 & $9(8,8)$ & $\begin{array}{l}\text { Kim et al., } \\
2006\end{array}$ \\
\hline EUA & $\begin{array}{c}\text { RT-PCR } \\
\text { hibridização } \\
\text { em placa }\end{array}$ & $\begin{array}{c}7 \text { rebanhos } \\
1 \\
\text { abatedouro }\end{array}$ & 1 mês a $>1$ ano & $\begin{array}{l}\text { diarréicas }(n=11) \\
\text { normais }(n=610)\end{array}$ & 621 & $389(62,0)$ & $\begin{array}{c}\text { Wang et al., } \\
2006 \mathrm{~b}\end{array}$ \\
\hline Hungria & RT-PCR & 2 rebanhos & $\begin{array}{c}\text { até } 12 \\
\text { dias }(n=8) \\
2 \text { a } 6 \text { meses } \\
(n=5) \\
2 \text { anos }(n=4)\end{array}$ & $\begin{array}{l}\text { diarréicas }(n=6) \\
\text { normais }(n=11)\end{array}$ & 17 & $2(11,8)$ & $\begin{array}{c}\text { Reuter, Bíró } \\
\text { e Szucs, } \\
2007\end{array}$ \\
\hline Japão & RT-PCR & $\begin{array}{c}\text { Coleção } \\
\text { de lab. } \\
\text { diagnóstico } \\
\text { veterinário }\end{array}$ & até 5 meses & diarréicas & 24 & $10(41,7)$ & $\begin{array}{l}\text { Yin et al., } \\
2006\end{array}$ \\
\hline Venezuela & RT-PCR & 7 rebanhos & 1 a 9 semanas & $\begin{array}{l}\text { diarréicas }(n=63) \\
\text { normais }(n=141)\end{array}$ & 204 & $36(17,6)$ & $\begin{array}{l}\text { Martínez et } \\
\text { al., } 2006\end{array}$ \\
\hline
\end{tabular}

Quadro 3. Freqüência de diagnóstico etiológico de sapovírus em fezes de suínos. 


\section{Agradecimentos}

Ao CNPq, CAPES, FINEP e Fundação Araucária pelo apoio financeiro. Alfieri, A.A. e Alfieri, A.F. Bolsista de Produtividade em Pesquisa do CNPq.

\section{Referências}

ADLER, J. L.; ZICKL, R. Winter vomiting disease. The Journal of Infectious Diseases, Chicago, v. 119, p. 668673, 1968.

ALMEIDA, J. D.; CRAIG, C. R.; HALL, T. E. Multiple viruses present in the faeces of a scouring calf. The Veterinary Record, London, v. 102, n. 8, p. 170-171, 1978.

ANDO, T.; NOEL, J. S.; FRANKHAUSER, R. L. Genetic classification of "Norwalk-like Viruses". The Journal of Infectious Diseases, Chicago, v. 181, Suppl. 2, p. 336348, 2000.

ATMAR,R.L.; ESTES,M.K.Diagnosis ofnoncultivatable gastroenteritis viruses, the human caliciviruses. Clinical Microbiology Reviews, Washington, v. 14, n. 1, p. 15-37, 2001.

BARRY, A. F. Freqüência de diagnóstico e caracterização molecular do calicivírus entérico suíno em rebanhos brasileiros. 2007. Dissertação. (Mestrado em Ciência Animal) - Universidade Estadual de Londrina, Londrina.

BARRY, A. F.; ALFIERI, A. F.; ALFIERI, A. A. Detection and phylogenetic analysis of porcine enteric calicivirus, genetically related to the Cowden strain of sapovirus genogroup III, in Brazilian swine herds. Brazilian Journal of Veterinary Research, Rio de Janeiro, v. 28, n. 1, p. 82-86, 2008.

BASCUÑANA, C. R.; NOWOTNY, N.; BELÁK, S. Detection and differentiation of rabbit hemorrhagic disease and european brown hare syndrome viruses by amplification of VP60 genomic sequences from fresh and fixed tissue specimens. Journal of Clinical Microbiology, Washington, v. 35, n. 10, p. 2492-2495, 1997.

BELLIOT, G.; SOSNOVTSEV, S. V.; MITRA, T.; HAMMER, C.; GARFIELD, M.; GREEN, K.Y. In vitro proteolytic processing of the MD145 norovirus ORF1 nonstructural polyprotein yields stable precursors and products similar to those detected in calicivirus-infected cells. Journal of Virology, Washington, v. 77, n. 20, p. 10957-10974, 2003.

BURROUGHS, J. N.; BROWN, F. Physico-chemical Evidence for the Re-classification of the Caliciviruses.
Journal of General Virology, London, v. 22, n. 2, p. 281286, Oct. 1974.

CLARKE, I. N.; LAMBDEN, P. R. Organization and expression of calicivirus genes. The Journal of Infectious Diseases, Chicago, v. 181, Suppl. 2, p. 309-316, 2000.

COSTANTINI, V. C.; LOISY, F.; JOENS, L.; LE GUYADER, F. S.; SAIF, L. J. Human and animal enteric calicivirus in oysters from different coastal regions of the United States. Applied and Environmental Microbiology, Washington, v. 72, n. 3, p. 1800-1809, 2006.

CUBITT, W. D. Caliciviruses. In: KAPIKIAN, A. Z. Viral infection of the gastrointestinal tract. 2.ed. New York: Marcel Dekker, 1994. p. 549-568.

CENTERS FOR DISEASE CONTROL AND PREVENTION - CDC. Norovirus outbreak among evacuees from hurricane Katrina - Houston, Texas, September 2005. MMWR Morbidity and Mortality Weekly Report, Atlanta, v. 54, p. 1016-1018, 2005.

CHANG, K. O.; SOSNOVTSEV, S. V.; BELLIOT, G.; KIM, Y.; SAIF, L. J.; GREEN, K. Y. Bile acids are essential for porcine enteric calicivirus replication in association with down-regulation of signal transducer and activator of transcription 1. Proceedings of the National Academy of Sciences of the United States of America, Washington, v. 101, n. 23, p. 8733-8738, 2004.

CHIBA, S.; NAKATA, S.; NUMATA-KINOSHITA, K.; HONMA, S. Sapporo virus: history and recent findings. The Journal of Infectious Diseases, Chicago, v. 181, Suppl. 2, p. 303-308, 2000.

DASTJERDI, A. M.; GREEN, J.; GALLIMORE, C. I.; BROWN, D. W. G.; BRIDGER, J. C. The bovine newbury agent-2 is genetically more closely related to human SRSVs than to animal caliciviruses. Virology, New York, v. 254, n. 1, p. 1-5, 1999.

DUIZER, E.; SCHWAB, K. J.; NEILL, F. H.; ATMAR, R. L.; KOOPMANS, M. P. G.; ESTES, M. K. Laboratory efforts to cultivate noroviruses. Journal of General Virology, London, v. 85, n. 1, p. 79-87, 2004.

EHRESMANN, D. W.; SCHAFFER, F. L. RNA synthesized in calicivirus-infected cells is atypical of picornaviruses. Journal of Virology, Washington, v. 22, n. 2, p. 572-576, 1977.

FARKAS, T.; ZHONG, W. M.; JING, Y.; HUANG, P. W.; ESPINOSA, S. M.; MARTINEZ, N.; MORROW, A. L.; RUIZ-PALACIOS, G. M.; PICKERING, L. K.; JIANG, $\mathrm{X}$. Genetic diversity among sapoviruses. Archives of Virology, New York, v. 149, p. 1309-1323, 2004.

FARKAS, T.; NAKAJIMA, S.; SUGIEDA, M.; DENG, X.; ZHONG, W.; JIANG, X. Seroprevalence of 
noroviruses in swine. Journal of Clinical Microbiology, Washington, v. 43, n. 2, p. 657-661, 2005.

FASTIER, L. B. A new feline virus isolated in tissue culture. American Journal of Veterinary Research, Chicago, v. 18, n. 67, p. 382-389, 1957.

FLYNN, W. T.; SAIF, L. J. Serial propagation of porcine enteric calicivirus-like virus in primary porcine kidney cell culturest. Journal of Clinical Microbiology, Washington, v. 26, n. 2, p. 206-212, 1988.

FLYNN, W. T.; SAIF, L. J.; MOORHEAD, P. D. Pathogenesis of porcine enteric calicivirus-like virus in four-day-old gnotobiotic pigs. American Journal of Veterinary Research, Chicago, v. 49, n. 6, p. 819-825, 1988.

FRANKHAUSER, R. L.; NOEL, J. S.; MONROE, S. S.; ANDO, T.; GLASS, R. I. Molecular epidemiology of "Norwalk-like Viruses" in outbreaks of gastroenteritis in the United States. The Journal of Infectious Diseases, Chicago, v. 178, n. 6, p. 1571-1578, 1998.

FRANKHAUSER, R. L.; MONROE, S. S.; NOEL, J. S.; HUMPHREY, C. D.; BRESSE, J. S.; PARASHAR, U. D.; ANDO, T.; GLASS, R. I. Epidemiologic and molecular trends of "Norwalk-like Viruses" associated with outbreaks of gastroenteritis in the United States. The Journal of Infectious Diseases, Chicago, v. 186, n. 1, p. 1-7, 2002.

GALLIMORE, C. I.; BARREIROS, M. A. B.; BROWN, D. W. G.; NASCIMENTO, J. P.; LEITE, J. P. G. Noroviruses associated with acute gastroenteritis in a children's day care facility in Rio de Janeiro, Brazil. Brazilian Journal of Medical and Biological Research, Ribeirão Preto, v. 37, n. 3, p. 321-326, 2004.

GOUGH, R. E.; SPACKMAN, D. Virus-like particles associated with disease in guinea fowl. The Veterinary Record, London, v. 109, n. 22, p. 497, 1981.

GREEN, K. Y.; ANDO, T.; BALAYAN, M. S.; BERKE, T.; CLARKE, I. N.; ESTES, M. K.; MATSON, D. O.; NAKATA, S.; NEILL, J. D.; STUDDERT, M. J.; THIEL, H. J. Taxonomy of the caliciviruses. The Journal of Infectious Diseases, Chicago, v. 181, Suppl. 2, p. 322330, 2000.

GREENBERG, H. B.; VALDESUSO, J. R.; KALIKA, A. R.; WYATT, R. G.; McAULIFFE, V. J.; KAPIKIAN, A. Z.; CHANOCK, R. M. Proteins of norwalk virus. Journal of Virology, Washington, v. 37, n. 3, p. 994-999, 1981.

GUO, M.; CHANG, K. O.; HARDY, M. E.; ZHANG, Q.; PARWANI, A. V.; SAIF, L. J. Molecular characterization of a porcine enteric calicivirus genetically related to Sapporo-like human caliciviruses. Journal of Virology, Washington, v. 73, n. 11, p. 9625-9631, 1999.
GUO, M.; EVERMANN, J. F.; SAIF, L. J. Detection and molecular characterization of cultivable caliciviruses from clinically normal mink and enteric caliciviruses associated with diarrhea in mink. Archives of Virology, New York, v. 146, n. 3, p. 479-493, 2001.

HANSMAN, G. S.; TAKEDA, N.; KATAYAMA, K.; TU, E. T. V.; McIVER, C. J.; RAWLINSON, W. D.; WHITE, P. A. Genetic diversity of sapovirus in children, Australia. Emerging Infectious Diseases, Atlanta, v. 12, n. 1, p. 141143, 2006.

INTERNATIONALCOMMITTEE ONTAXONOMY OF VIRUSES - ICTV. ICTVdB: the universal virus database: version 4. Disponível em: $<$ http://www.ncbi.nlm.nih.gov/ ICTVdb/ICTVdB/>. Acesso em: 21 jan. 2007.

INOUYE, S.; YAMASHITA, K.; YAMADERA, S.; YOSHIKAWA, M.; KATO, N.; OKABE, N. Surveillance of viral gastroenteritis in Japan: pediatric cases and outbreak incidents. The Journal of Infectious Diseases, Chicago, v. 181, Suppl. 2, p. 270-274, 2000.

ISAKBAEVA, E. T.; WIDDOWSON, M. A.; BEARD, R. S.; BULENS, S. N.; MULLINS, J.; MONROE, S. S.; BRESEE, J.; SASSANO, P.; CRAMER, E. H.; GLASS, R. I. Norovirus transmission on cruise ship. Emerging Infectious Diseases, Atlanta, v. 11, n. 1, p. 154-157, 2005.

JIANG, X.; HUANG, P. W.; ZHONG, W. M.; FARKAS, T.; CUBITT, D. W.; MATSON, D. O. Design and evaluation of a primer pair that detects both norwalkand Sapporo-like caliciviruses by RT-PCR. Journal of Virological Methods, Amsterdam, v. 83, n. 1-2, p. 145 154, 1999.

KAPIKIAN, A. Z.; WYATT, R. G.; DOLIN， R.; THORNHILL, T. S.; KALICA, A. R.; CHANOCK, R. M. Visualization by immune electron microscopy of a $27-$ $\mathrm{nm}$ particle associated with acute infectious nonbacterial gastroenteritis. Journal of Virology, Washington, v. 10, n. 5, p. 1075-1081, 1972.

KARST, S. M.; WOBUS, C. E.; LAY, M.; DAVIDSON, J.; VIRGIN IV, H. W. STAT1-dependent innate immunity to a norwalk-like virus. Science, Washington, v. 299, n. 5612, p. 1575-1578, 2003.

KIM, H. J.; CHO, H. S.; CHO, K. O.; PARK, N. Y. Detection and molecular characterization of porcine enteric calicivirus in Korea, genetically related to sapoviruses. Journal of Veterinary Medicine. Series B Infectious Diseases and Veterinary Public Health, Berlin, v. 53 , n. 4 , p. $155-159,2006$.

LAVAZZA, A.; VECCHI, G. Osservazioni su alcuni episodi di mortalita nella lepre evidenziazione al microscopio elettronico di una particella virale. Nota preliminare. Estratto da Selezione Veterinaria, Brescia, Italia, v. 30, n. 3, p. 461-468, 1989. 
LONG, G. G.; EVERMANN, J. F.; GORHAM, J. R. Naturally occurring picornavirus infection of domestic mink. Canadian Journal of Comparative Medicine, Ottawa, v. 44, n. 4, p. 412-417, 1980.

LOPMAN, B. A.; REACHER, M. H.; VAN DUIJNHOVEN, Y.; HANON, F. X.; BROWN, D.; KOOPMANS, M. Viral gastroenteritis outbreaks in Europe, 1995-2000. Emerging Infectious Diseases, Atlanta, v. 9, n. 1, p. 90-96, 2003.

LIU, B. L.; LAMBDEN, P. R.; GÜNTER, H.; OTTO, P.; ELSCHNER, M.; CLARKE, I. N. Molecular characterization of a bovine enteric calicivirus: relationship to the norwalk-like viruses. Journal of Virology, Washington, v. 73, n. 1, p. 819-825, 1999.

LIU, S. J.; XUE, H. P.; PU, B. Q.; QIAN, N. H. A new viral disease in rabbits. Animal Husbandry and Veterinary Medicine, Taiwan, v. 16, n. 6, p. 253-255, 1984.

MADELEY, C. R.; COSGROVE, B. P. Caliciviruses in man. The Lancet, London, v. 307, n. 7952, p. 199-200, 1976.

MADIN, S. H.; TRAUM, J. Vesicular exanthema of swine. Bacteriological Reviews, Baltimore, v. 19, n. 1, p. 6-21, 1955.

MARTIN-ALONSO, J. M.; SKILLING, D. E.; GONZALEZ-MOLLEDA, L.; DEL BARRIO, G.; MACHIN, A.; KEEFER, N. K.; MATSON, D. O.; IVERSEN, P. L.; SMITH, A. W.; PARRA, F. Isolation and characterization of a new vesivirus from rabbits. Virology, New York, v. 337, n. 2, p. 373-383, 2005.

MARTÍNEZ, M. A.; ALCALÁ, A. C.; CARRUYO, G.; BOTERO, L.; LIPRANDI, F.; LUDERT, J. E. Molecular detection of porcine enteric caliciviruses in Venezuelan farms. Veterinary Microbiology, Amsterdam, v. 116, n. 1-3, p. 77-84, 2006.

MOHLER, J. R.; SNYDER, R. The 1932 outbreak of footand-mouth disease in Southern California. Miscellaneous Publications: United States Department of Agriculture, Washington, v. 163, n. 1, p. 1-10, 1933.

NAKAMURA, L. S.; OLIVEIRA, D. S.; SILVA, P. F.; LUCENA, M. S.; MASCARENHAS, J. D. P.; GUSMÃO, R. H. P.; LINHARES, A. C.; GABBAY, Y. B. Molecular characterization of calicivirus in feces of children with acute diarrhea, attending a public hospital, in BelémPará. In: NATIONAL MEETING OF VIROLOGY, 17., 2006, Campos do Jordão. Anais... São Paulo: Sociedade Brasileira de Virologia, 2006. p. 95.

NEILL, J. D.; MEYER, R. F.; SEAL, B. S. Genetic relatedness of the caliciviruses: San Miguel Sea Lion and vesicular exanthema of swine viruses constitute a single genotype within the Caliciviridae. Journal of Virology, Washington, v. 67, n. 7, p. 4484-4488, 1995.
OHLINGER, V.F.; HAAS, B.; MEYERS, G.; WEILAND, F.; THIEL, H. J. Identification and characterization of the virus causing rabbit hemorrhagic disease. Journal of Virology, Washington, v. 64, n. 7, p. 3331-3336, 1990.

OKA, T.; KATAYAMA, K.; OGAWA, S.; HANSMAN, G. S.; KAGEYAMA, T.; USHIJIMA, H.; MIYAMURA, T.; TAKEDA, N. Proteolitic processing of sapovirus ORF1 polyprotein. Journal of Virology, Washington, v. 79, n. 12, p. 7283-7290, 2005.

OKADA, M.; SHINOZAKI, K.; OGAWA, T.; KAIHO, I. Molecular epidemiology and phylogenetic analysis of Sapporo-like viruses. Archives of Virology, New York, v. 147, n. 7, p. 1445-1451, 2002.

OKADA, M.; YAMASHITA, Y.; OSETO, M.; SHINOZAKI, K. The detection of human sapoviruses with universal and genogroup-specific primers. Archives of Virology, New York, v. 151, n. 12, p. 2503-2509, 2006.

PARWANI, A. V.; FLYNN, W. T.; GADFIELD, K. L.; SAIF, L. J. Serial propagation of porcine enteric calicivirus in a continuous cell line. Archives of Virology, New York, v. 120, n. 1-2, p. 115-122, 1991.

REUTER, G.; BÍRÓ, H.; SZÜCS, G. Enteric caliciviruses in domestic pigs in Hungary. Archives of Virology, New York, v. 152, n. 3, p. 611-614, 2007.

SAIF, L. J.; BOHL, E. H.; THEIL, K. W.; CROSS, R. F.; HOUSE, J. A. Rotavirus-like, calicivirus-like, and 23$\mathrm{nm}$ virus-like particles associated with diarrhea in young pigs. Journal of Clinical Microbiology, Washington, v. 12, n. 1, p. 105-111, 1980.

SCHAFFER, F. L.; SOERGEL, M. E.; BLACK, J. W.; SKILliNG, D. E.; SMITH, A. W.; CUBITT, W. D. Characterization of a new calicivirus isolated from feces of a dog. Archives of Virology, New York, v. 84, n. 3-4, p. 181-195, 1985.

SCHUFFENECKER, I.; ANDO, T.; THOUVENOT, D.; LINA, B.; AYMARD, M. Genetic classification of "Sapporo-like viruses". Archives of Virology, New York, v. 146, n. 11, p. 2115-2132, 2001.

SEAL, B. S.; LUTZE-WALLACE, C.; KREUTZ, L. C.; SAPP, T.; DULAC, G. C.; NEILL, J. D. Isolation of caliciviruses from skunks that are antigenically and genotypically related to San Miguel sea lion virus. Virus Research, Amsterdam, v. 37, n. 1, p. 1-12, 1995.

SMILEY, J. R.; CHANG, K. O.; HAYES, J.; VINJÉ, J.; SAIF, L.J. Characterization of an Enteropathogenic Bovine Calicivirus Representing a Potential New Calicivirus Genus. Journal of Virology, Washington, v. 76 n. 20, p. 10089-10098, 2002. 
SMITH, A. W.; AKERS, T. G.; MADIN, S. H.; VEDROS, N. A. San Miguel sea lion virus isolation, preliminary characterization and relationship to vesicular exanthema of swine virus. Nature, London, v. 244, p. 108-110, 1973.

SMITH, A. W.; MATTSON, D. E.; SKILLING, D. E.; SCHMITZ, J. A. Isolation and partial characterization of a calicivirus from calves. American Journal of Veterinary Research, Chicago, v. 44, n. 5, p. 851-855, 1983 a.

SMITH, A. W.; SKILLING, D. E.; ENSLEY, P. K.; BENIRSCHKE, K.; LESTER, T. L. Calicivirus isolation and persistence in a pygmy chimpanzee (Pan paniscus). Science, Washington, v. 221, n. 4605, p. 79-81, 1983 b.

SMITH, A. W.; SKILLING, D. E.; RIDGWAY, S. Calicivirus-induced vesicular disease in cetaceans and probable interspecies transmission. Journal of American Veterinary Medical Association, Ithaca, v. 183, n. 11, p. 1223-1225, 1983.

SMITH, A. W.; ANDERSON, M. P.; SKILling, D. E.; BARLOUGH, J. E.; ENSLEY, P. K. First isolation of calicivirus from reptiles and amphibians. American Journal of Veterinary Research, Chicago, v. 47, n. 8, p. 1718-1721, 1986.

SOSNOVTSEV, S. V.; GARFIELD, M.; GREEN, K. Y. Processing map and essential cleavage sites of the nonstructural polyprotein encoded by ORF1 of the feline calicivirus genome. Journal of Virology, Washington, v. 76 n. 14, p. 7060-7072, 2002.

SUGIEDA, M.; NAGAOKA, H.; KAKISHIMA, Y; OHSHITA, T.; NAKAMURA, S.; NAKAJIMA, S. Detection of norwalk-like virus genes in the caecum contents of pigs. Archives of Virology, New York, v. 143, n. 6, p. 1215-1221, 1998.

SUGIEDA, M.; NAKAJIMA, S. Viruses detected in the caecum contents of healthy pigs representing a new genetic cluster in genogroup II of the genus 'Norwalklike viruses'. Virus Research, Amsterdam, v. 87, n. 2, p. 165-172, 2002.

THUMFART, J. O.; MEYERS, G. Feline calicivirus: recovery of wild-type and recombinant viruses after transfection of cRNA or cDNA constructs. Journal of Virology, Washington, v. 76, n. 12, p. 6398-6407, 2002.

WANG, Q. W.; HAN, M. G.; FUNK, J. A.; BOWMAN, G.; JANIES, D. A.; SAIF, L. J. Genetic diversity and recombination of porcine sapoviruses. Journal of Clinical Microbiology, Washington, v. 43, n. 12, p. 5963-5972, 2005.

WANG, Q. W.; CHANG, K. O.; HAN, M. G.; SREEVATSAN, S.; SAIF, L. J. Development of a new microwell hybridization assay and an internal control RNA for the detection of porcine noroviruses and sapoviruses by reverse transcription-PCR. Journal of Virological Methods, Amsterdam, v. 132, n. 1-2, p. 135145, 2006a.

WANG, Q. W.; SOUZA, M.; FUNK, J. A.; ZHANG, W.; SAIF, L. J. Prevalence of noroviruses and sapoviruses in swine of various ages determined by reverse transcriptionPCR and microwell hybridization assays. Journal of Clinical Microbiology, Washington, v. 44, n. 6, p. $2057-$ 2062, 2006 b.

WANG, Q. W.; COSTANTINI, V.; SAIF, L. J. Porcine enteric caliciviruses: genetic and antigenic relatedness to human caliciviruses, diagnosis and epidemiology. Vaccine, Kidlinton, v. 25, n. 30, p. 5453-5466, 2007.

WILDER, F. W.; DARDIRI, A. H. San Miguel sea Lion virus fed to mink and pigs. Canadian Journal of Comparative Medicine, Ottawa, v. 42, n. 2, p. 200-204, 1978.

WIRBLICH, C.; MEYERS, G.; OHLINGER, V. F.; CAPUCCI, L.; ESKENS, U.; HAAS, B.; THIEL, H. J. European brown hare syndrome virus: relationship to rabbit hemorrhagic disease virus and other caliciviruses. Journal of Virology, Washington, v. 68, n. 8, p. 51645173, 1994.

WIRBLICH, C.; THIEL, H. J.; MEYERS, G. Genetic map of the calicivirus rabbit hemorrhagic disease virus as deduced from In vitro translation studies. Journal of Virology, Washington, v. 70, n. 11, p. 7974-7983, 1996.

WOBUS, C. E.; KARST, S. M.; THACKRAY, L. B.; CHANG, K. O.; SOSNOVTSEV, S. V.; BELLIOT, G.; KRUG, A.; MACKENZIE, J. M.; GREEN, K. Y.; VIRGIN IV, H. W. Replication of norovirus in cell culture reveals a tropism for dendritic cells and macrophages. Public Library of Science Biology, San Francisco, v. 2, n. 12, p. 2076-2084, 2004.

WOBUS, C. E.; THACKRAY, L. B.; VIRGIN IV, H. W. Murine norovirus: a model system to study norovirus biology and pathogenesis. Journal of Virology, Washington, v. 80, n. 11, p. 5104-5112, 2006.

YIN, Y.; TOHYA, Y.; OGAWA, Y.; NUMAZAWA, D.; KATO, K.; AKASHI, H. Genetic analysis of calicivirus genomes detected in intestinal contents of piglets in Japan. Archives of Virology, New York, v. 151, n. 9, p. 1749-1759, 2006.

ZHENG, D. P.; ANDO, T.; FRANKHAUSER, R. L.; BEARD, R. S.; GLASS, R. I.; MONROE, S. S. Norovirus classification and proposed strain nomenclature. Virology, New York, v. 346, n. 2, p. 312-323, 2006. 